\title{
3-D High-Lift Flow-Physics Experiment - Transition Measurements
}

\author{
Catherine B. McGinley ${ }^{*}$, Luther N. Jenkins ${ }^{\dagger}$, Ralph D. Watson ${ }^{\ddagger}$ \\ NASA Langley Research Center, Hampton, Virginia, 23681 \\ Arild Bertelrud ${ }^{\S}$ \\ Analytical Services and Materials, Inc., Hampton, Virginia, 23666
}

\begin{abstract}
An analysis of the flow state on a trapezoidal wing model from the NASA 3-D High Lift Flow Physics Experiment is presented. The objective of the experiment was to characterize the flow over a non-proprietary semi-span three-element high-lift configuration to aid in assessing the state of the art in the computation of three-dimensional high-lift flows. Surface pressures and hot-film sensors are used to determine the flow conditions on the slat, main, and flap. The locations of the attachments lines and the values of the attachment line Reynolds number are estimated based on the model surface pressures. Data from the hotfilms are used to determine if the flow is laminar, transitional, or turbulent by examining the hot-film time histories, statistics, and frequency spectra.
\end{abstract}

\section{Nomenclature}

c $=$ mean aerodynamic chord

$\mathrm{C}_{\mathrm{L}} \quad=$ lift coefficient

$C_{p} \quad=$ pressure coefficient

$K=$ relaminarization parameter

$\mathrm{M} \quad=$ Mach Number

$\overline{\mathrm{R}}=$ attachment line Reynolds number

$\mathrm{R}_{\mathrm{c}}=$ chord Reynolds number

$\mathrm{s}=$ surface coordinate

$\mathrm{S}_{\mathrm{ee}} \quad=$ power spectral density

$\mathrm{U}_{\infty} \quad=\quad$ free stream velocity

$\mathrm{X} \quad=$ streamwise coordinate

\footnotetext{
* Aerospace Engineer, Flow Physics and Control Branch, MS 170, Member AIAA

${ }^{\dagger}$ Aerospace Engineer, Flow Physics and Control Branch, MS 170

* Aerospace Engineer, Flow Physics and Control Branch, MS 170, Senior Member AIAA

$\S$ Aerospace Engineer, Analytical Services and Materials, Inc, 107 Research Drive, Member AIAA 


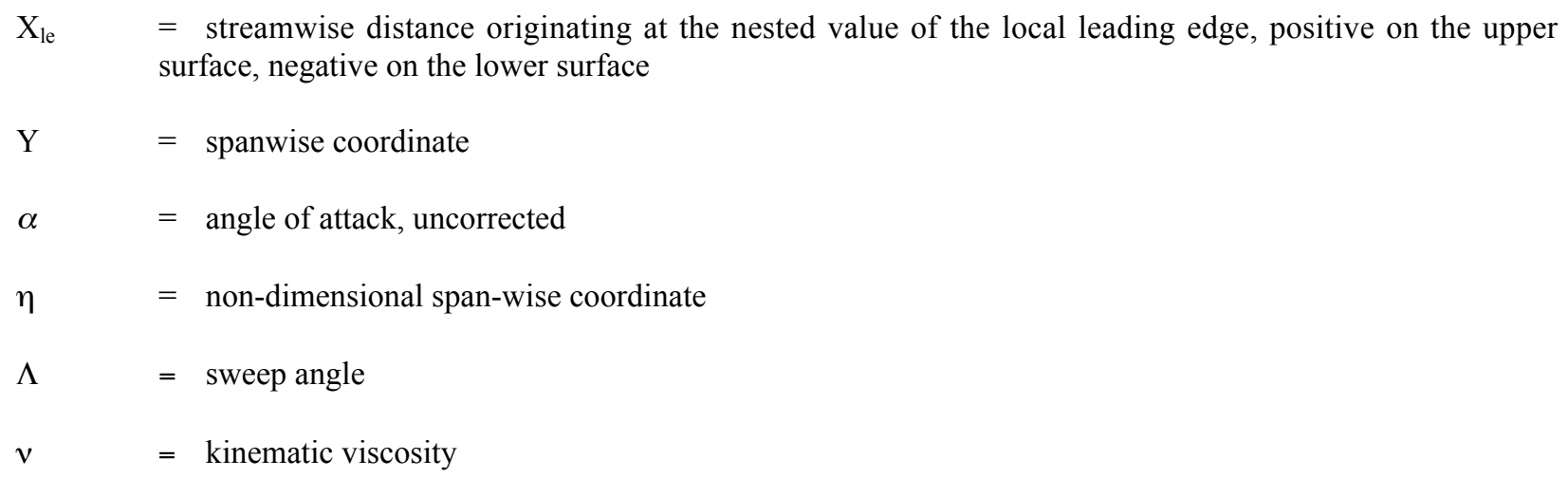

\section{Introduction}

Accurate prediction of the flow over high-lift configurations is a long sought after goal of the aerospace industry. If designers could accurately predict the performance of high-lift systems it would enhance their ability to create more efficient designs. The flow field around a high-lift system contains many aspects of fluid dynamics that challenge modern CFD codes. The complex flow field that encompasses a swept high-lift configuration includes such challenging conditions as attachment line flow, transition, relaminarization, separation, reattachment, wake/boundary-layer merging, shock/boundary layer interaction, and flow curvature. By testing their codes against experimental high-lift data, code developers can improve their codes for many applications.

Early efforts aimed at improving high-lift predictions were focused on understanding two-dimensional configurations. For example, a rather complete study of a 2-D case was documented in the experiments and computations conducted on the MDA $30 \mathrm{P} 30 \mathrm{~N}$ configuration ${ }^{1}$. Along with the traditional data such as pressures, forces, and moments, more detailed data were obtained in the form of transition, separation, and reattachment locations $^{2}$ as well as Reynolds stress profiles ${ }^{3}$. Comparing these experiments to computational predictions helped reveal where the CFD codes were doing well and where improvement was needed. Data obtained by hot-wire measurements, for example, showed that unsteady flow in the slat cove at low angle of attack was unaccounted for in CFD predictions. Comparisons of experimental and computational Reynolds stress profiles showed that the turbulence models were doing a better job than expected, but that improvements might be achieved in areas such as flow curvature ${ }^{4}$. Incorporation of the measured transition locations into CFD codes ${ }^{5}$ demonstrated that when the measured transition locations were used in the computation, the slat wake was not correctly predicted. They concluded that further research was needed in the implementation of transition in high-lift CFD computations

Two examples of 3-D high-lift studies involving transition are the experiments conducted under EUROLIFT ${ }^{6}$ and the NASA 737 Experiment ${ }^{7}$. In the EUROLIFT wind-tunnel experiment, twenty-four hot-film sensors and infrared thermography were used to document transition. Various sweep angles and Reynolds numbers were tested in order to study transition at various states of the attachment line. They were able to show transition due to contamination and possible relaminarization under certain conditions. Three-Dimensional Reynolds-Averaged Navier-Stokes solutions and stability computations have been performed and compared to the experimental data in an ongoing process to improve overall prediction accuracy. The purpose of the 737 flight experiment was to examine the complex flow conditions of a five-element high-lift system at flight Reynolds numbers. Ninety-eight hot-film sensors and infrared thermography were used to acquire transition data during accelerations and decelerations. Examples of hot-film signals attributed to transition due to cross-flow and Tollmien-Schlichting instabilities, attachment line transition, and relaminarization were given.

In this paper we examine the features of the flow over a trapezoidal planform high-lift wing through the use of surface pressures and hot-films. Two important parameters can be determined from the surface pressure measurements to give an indication of the flow state on the swept wing, the attachment line Reynolds number and the relaminarization parameter. The attachment line Reynolds number ${ }^{8}$ is defined as, 


$$
\overline{\mathrm{R}}=\frac{\mathrm{W}_{\infty} \kappa}{v}, \text { where } \kappa=\left(\frac{v}{U_{n}^{\prime}}\right)^{0.5}, W_{\infty}=U_{\infty} \sin \Lambda, \quad U_{n}^{\prime}=\frac{\partial U_{n}}{\partial s}
$$

and $U_{n}$ is the velocity component normal to the leading edge. For values below approximately $\bar{R}=245$ the attachment line will remain laminar and any disturbances will be damped out. For values in the range of $245>\bar{R}>$ 580 the flow can be laminar, transitional, or turbulent. Depending on their strength, certain disturbances such as roughness and free stream noise can become amplified and lead to transition. Above $\overline{\mathrm{R}}>580$ the attachment line will likely be turbulent. Theses limits for $\overline{\mathrm{R}}$ were determined from investigations on infinite swept wings and cylinders. While not definitive limits for a tapered swept wing in the high-lift configuration, they still serve as a useful guide as to the state of the attachment line. The relaminarization parameter ${ }^{9}$ is defined as,

$$
K=\left(\frac{v}{U_{e}}\right) \frac{\partial U e}{\partial s},
$$

where $\mathrm{U}_{\mathrm{e}}$ is the edge velocity following a streamline. It is generally held that for 2-D flow that if $K \geq 3 \times 10^{-6}$, for a sufficient distance, then relaminarization is likely. Unfortunately, there are no useful limits defining how much distance is considered significant. The applicability of this factor is still under active investigation. For instance, Bourassa, et $\mathrm{al}^{10}$ suggested that $K$ was not a reliable indicator of relaminarization and suggested parameters obtained from off surface measurements. Viswanath, et $\mathrm{al}^{11}$ suggested that the parameter be modified by the cosine of the angle between the resultant edge velocity and the edge velocity normal to the leading edge.

The determination of transition is usually accomplished via time-dependent point-wise measurements such as hot-films or hot-wires, and/or global visualization methods such as infrared thermography (IR), liquid crystals, or sublimating chemicals. Bertelrud ${ }^{12}$ describes the use of hot-films for the detection of transition. The hot film is sensitive to the instantaneous shear stress. While not a quantitative measure of the shear stress it can give significant insight into the state of transition. The standard deviation of the hot-film signal will usually rise significantly as transition occurs and then fall to a lower state under fully turbulent conditions (but still well above the laminar level). The skewness, the third statistical moment, will change sign, becoming positive at the beginning of transition and then negative with a final return to zero at the end. The power spectrum can be used to determine how the energy is spread over the frequency range. Laminar and transitional boundary layers typically display spectra that are not as full as a turbulent spectrum. No one indicator is usually sufficient to determine transition. All of these parameters can be affected by other features in the flow, therefore as many as possible should be examined to determine the flow state. Cross-correlations of hot-film sensors can also be used to sense flow direction. This is especially useful in 2-D flow to determine separation and reattachment. In 2-D flows one relies on the phase shift between sensors and the zero correlation of sensors on either side of the dividing streamline. A three-dimensional flow does not always have such definitive characteristics.

The use of the global techniques of IR and liquid crystals and how they compare with hot-films was studied by Stanfield and Betts ${ }^{13}$. They found that the transition locations determined by IR and hot-films were in general agreement. They cautioned that improper illumination of the liquid crystals could lead to poor results. Dagenhart, et $\mathrm{al}^{14}$ used sublimating chemicals/naphthalene, liquid crystals, and hot-films to study cross-flow transition. They found general agreement between the sublimating chemicals and the hot-films. They also found the sublimating chemical technique to be superior to the liquid crystals. The draw back to the naphthalene technique is that it can only document one condition at a time and would therefore be a costly method of determining transition in a large/expensive wind tunnel. Ideally, a global technique should be used in conjunction with the hot-film technique. In our test, we attempted to use liquid crystals to determine the transition locations, but limitations on the illumination angle precluded useful transition measurements. The images did prove useful, however, in tracking the path of the slat bracket wakes over the model and films.

The purpose of the 3-D High-Lift Flow-Physics Experiment is to investigate flow physics and provide nonproprietary data to the computational fluid dynamics (CFD) community to improve the understanding and prediction of the flow over a swept three-element high-lift configuration. This study was initially funded under the Aerospace Systems Concept to Test (ASCoT) Project and then continued under the Efficient Aerodynamics Shapes and Integration (EASI) Project. The current experiment was devised to provide a comprehensive set of non-proprietary 
data on a 3-D high lift model to be used to improve computational predictions. The data obtained includes tunnel inflow and out-flow conditions, tunnel free-stream turbulence levels ${ }^{15}$, model surface, and flow field (Particle Image Velocimetry) data. Two experiments using the same model were conducted previous to this test in the NASA Langley 14- by 22-Foot Subsonic Tunnel and in the NASA Ames 12FT Pressure Wind Tunnel ${ }^{16,17}$ in a joint NASA/Boeing study funded under the Advanced Subsonic Transport (AST) program. While in the previous tests they examined a variety of slat and flap settings, in our test we focused on obtaining detailed flow information on one configuration, a slat setting of $30^{\circ}$ and a flap setting of $25^{\circ}$. Our model configuration differed slightly from that tested during the AST program in that our flap overlap, as a percentage of the local stowed chord, was approximately $50 \%$ less than the setting that they tested. Results from the Ames experiment showed that significant blockage effects were present in the data and that it was necessary to model the wind tunnel in order for the computations to match the experimental data. In the previous Langley experiment (AST), limited IR transition data were obtained and will be compared to the results from our experiment.

In this paper we will describe the data obtained on the surface of a 3-D high-lift model, specifically the pressures and hot film data. The discussion is limited to determining, to the extent possible, where the flow is laminar, transitional, or turbulent. We acknowledge the possible existence of separation bubbles on the model, however, that discussion is beyond the scope of this paper. The present discussion will generally focus on three angles of attack, $\alpha=12^{\circ}, 16^{\circ}$, and $24^{\circ}$, although data at other angles are included when needed to establish trends. These angles were chosen for analysis because both flow field and transition data were acquired at these angles and would therefore be available for comparison when the flow field analysis is completed.

\section{Experimental Apparatus}

The experiment was conducted in the NASA Langley 14- by 22-Foot Subsonic Tunnel in the closed configuration $^{18}$. The model was installed on a standoff pod on the floor of the wind tunnel as shown in Fig. 1. The model semi-span is $2.16 \mathrm{~m}$ and the mean aerodynamic chord is $1.01 \mathrm{~m}$. The test conditions for the experiment were $\mathrm{M}=0.2$, and $\mathrm{R}_{\mathrm{c}}=4.2 \times 10^{6}$. A Boundary Layer Removal System (BLRS) was used to suction off the boundary layer on the floor at the entrance to the test section. The model was mounted on a 5-component balance to acquire force and moment data. The model contains 832 pressure taps, however not all pressure taps were functioning during the test. The pressure and balance data were acquired with no hot-films on the model. Five hundred hot-film sensors were installed on the model for this test in a variety of configurations depending on their location on the wing. The films were installed in two stages. First the flap and the aft portion of the main element were instrumented and data were acquired. Next, additional films were added upstream on the main element and slat until the entire model was instrumented. This was done to determine if the films upstream changed the character of the flow detected at the downstream elements. With the exception of a small group of sensors on the flap near to the floor and a bracket, the data were qualitatively the same for both configurations. The active elements of the hot-film sensors were composed of Nickel that was deposited on a polyimide substrate. The total thickness of the sheet and the glue used to adhere the sheet to the surface was $0.1 \mathrm{~mm}$.

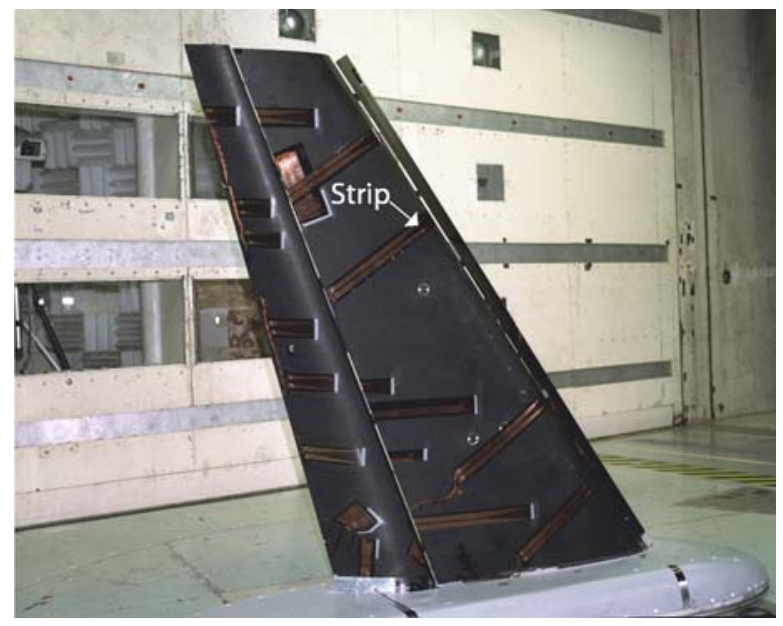

Figure 1. Trap Wing model in $14 \times 22$ wind tunnel, model upper surface shown.
The hot-film sensors were grouped together as 40 objects in four types of configurations: strips, patches, stamps, and arrays. The strip objects are shown in Fig. 1 (near the leading edge of the main element) and contained various numbers of films aligned in a single row. The strips contained widely spaced films intended to cover large distances. The remaining objects contained closely spaced films to examine finer details. The patches, Fig. 2, contained six films aligned in a row and two films offset at $45^{\circ}$ to sense flow direction. Arrays, Fig. 3, contained 24 films arranged in two rows of twelve sensors aligned $90^{\circ}$ to each other. Stamps, Fig. 4, contained four films aligned in a row. Twenty-four constant temperature anemometers ${ }^{19}$ controlled the films. Films from the various objects were arranged in 22 groups of 24 and 
connected to the films through switches. The films and the leads to the anemometer were designed so that films would have similar resistances. This enabled the anemometers to be switched between the film groups without any need for retuning the anemometers. A great degree of care was taken to lower the electronic noise level of the complete system. The noise floor of the system was approximately 2 millivolts. The hot film data were acquired in 100 blocks of 2048 points at sample rates of $25.6 \mathrm{kHz}$ or $51.2 \mathrm{kHz}$.

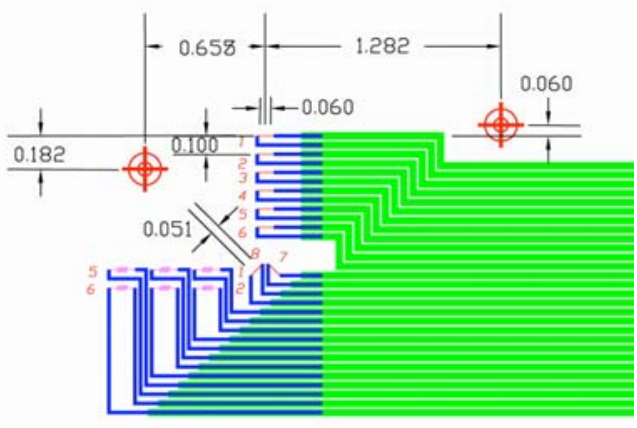

PATCH

Figure 2. Hot-film patch object, dimensions in inches.

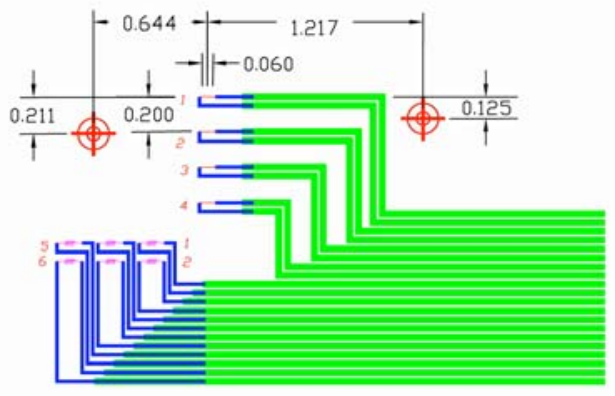

STAMP

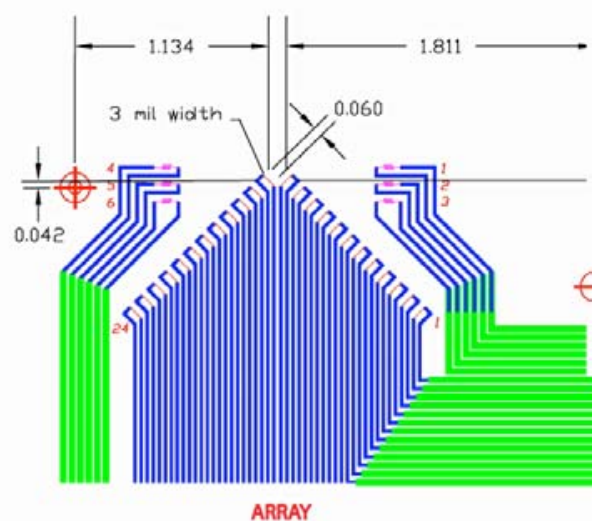

Figure 3. Hot-film array object, dimensions in inches.

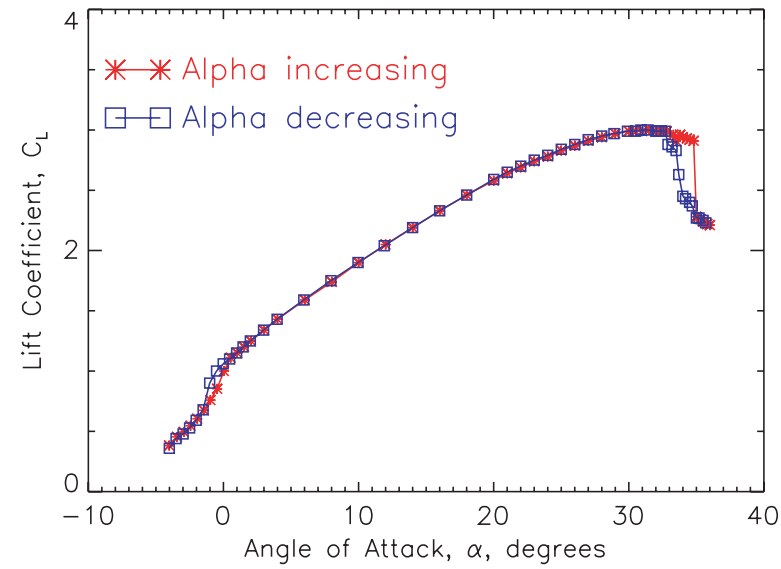

Figure 5. Lift coefficient versus Angle of Attack.

Figure 4. Hot-film stamp object, dimensions in inches.

\section{Results and Discussion}

The change in the lift coefficient with angle of attack is shown in Fig. 5 where the data were acquired in pitchpause mode, first while the angle of attack was increasing and then deceasing. Two areas of hysteresis appear at $-1.5^{\circ}<\alpha<-0.5^{\circ}$ and $32.7^{\circ}<\alpha<35.0^{\circ}$. The presence of hysteresis is sometimes an indication of the bursting of a 
separation bubble. As indicated earlier, however, the presence of separation bubbles will not be discussed in this paper.

The pressures on the slat are shown in Figs. 6 and 7. Figure 6 shows the spanwise variation of the pressure at $\alpha$ $=24^{\circ}$. At $\eta=0.17$ the pressures are affected by the proximity to the pod and the tunnel floor. The pressure coefficient peaks at $\eta=0.65$ and 0.85 and then decreases again at $\eta=0.95$. In Fig. 7 the effect of changing the angle of attack on the pressures at $\eta=0.41$ is shown. (This station was chosen because it is close an upper surface film object.) At $\alpha=8^{\circ}$ the suction peak is just arriving on the upper surface. In fact, it is not until $\alpha=12^{\circ}$ that the slat starts loading in the positive lift direction across the entire span of the slat. At $\alpha=24^{\circ}$ the suction peak is easily discernable.

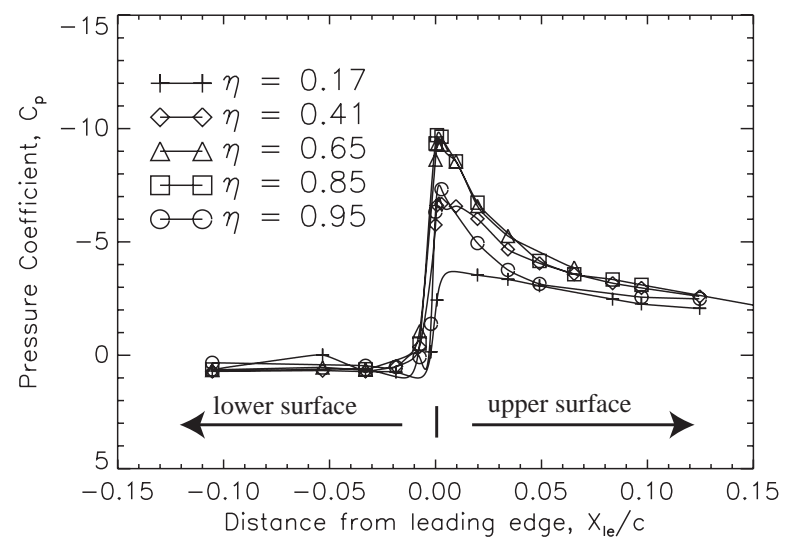

Figure 6. Slat pressure coefficient at $\alpha=24^{\circ}$.

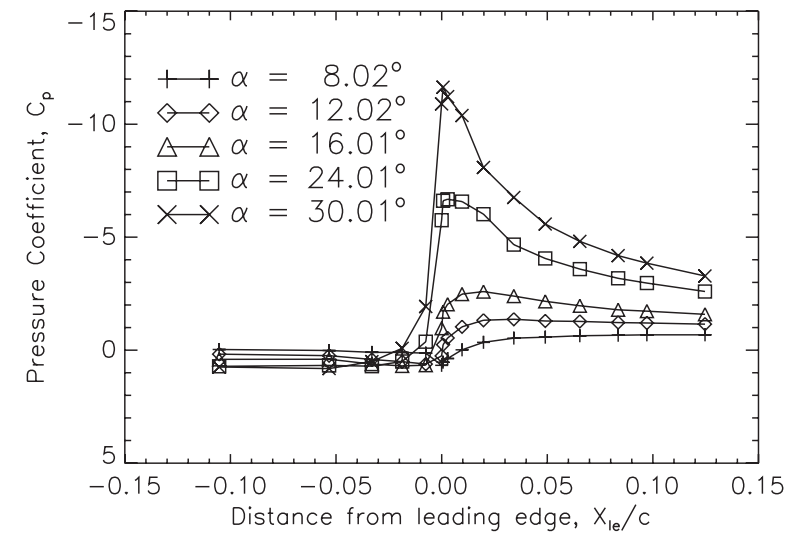

Figure 7. Slat pressure coefficient at $\eta=0.41$

The attachment line locations were estimated from the experimental pressures. Following the procedure described by Bertelrud and Graves ${ }^{20}$, the local velocity is calculated from the pressure distributions. First the point of maximum pressure is found. Next the velocities are calculated and then velocities to the left of the maximum pressure location are given a negative sign. Then, in an iterative process based on the effective sweep angle, the attachment line is located as the point where the velocity normal to the leading edge is zero. Once the attachment line location is determined the value of $\overline{\mathrm{R}}$ is calculated at that location. The $\overline{\mathrm{R}}$ values for the slat are shown in Fig. 8. Below $\alpha=2^{\circ}$, the values fall above the criteria for laminar flow. At $\alpha=12^{\circ}, 16^{\circ}$, and $24^{\circ}$ the values are below or close to the limit. The estimated attachment line locations for the slat at $\alpha=12^{\circ}, 16^{\circ}$, and $24^{\circ}$ are shown in Fig. 9 with respect to three film objects $(34,38$, and 39) located on the lower surface of the slat. As expected the

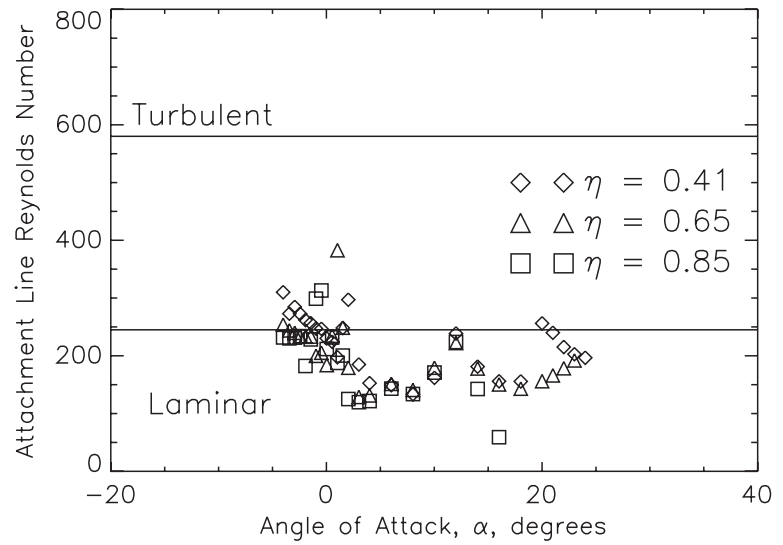

Figure 8. Slat attachment line Reynolds number, $\overline{\mathrm{R}}$, versus angle of attack.

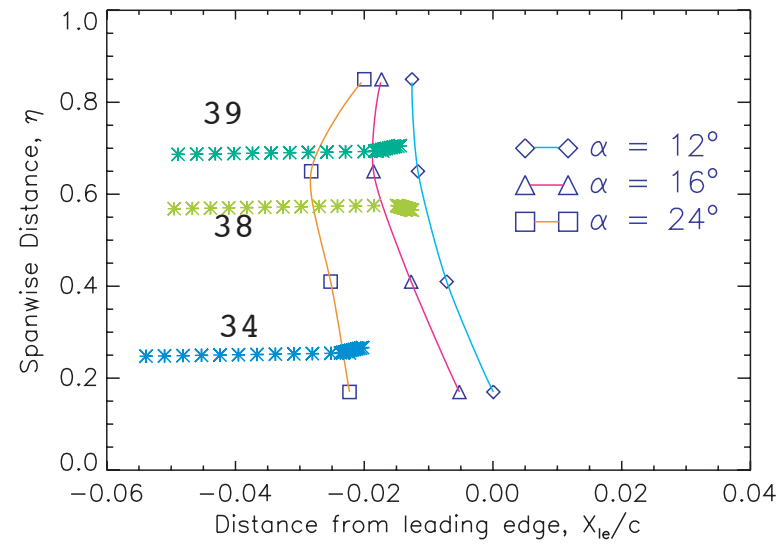

Figure 9. Relative locations of the slat attachment lines and the hot-films on the lower surface. Data for $\alpha=24^{\circ}$ are qualitative. 
attachment line moves toward the cusp of the slat with increasing angle of attack. The values of the attachment line locations at $\alpha=24^{\circ}$ are only qualitative due to the lack of pressure ports in the area and the flatness of the pressure coefficient with respect to the surface distance. The flat pressure profile on the lower surface of the slat at high angles of attack made the choice of the maximum pressure location fairly arbitrary. Also, the value at $\eta=0.65$ and $\alpha=24^{\circ}$ was extrapolated from data acquired at lower angles of attack because no solution for that station could be obtained by the above method.

The accuracy of method for determining the attachment line location was tested at $\alpha=12^{\circ}$ and $\eta=0.65 \quad(\eta=$ 0.65 was chosen because it had the largest pressure port spacing) by using a preliminary computational solution ${ }^{* *}$ to assess the impact of port spacing and location on the experimental determination of the attachment line location and the value of $\bar{R}$. The computational solution was used to mimic a data set with very dense port spacing and the attachment line location and $\bar{R}$ were computed. Next, $C_{p}$ values near the experimental port locations were extracted from the computational solution and the attachment line location and $\overline{\mathrm{R}}$ were again computed. The difference between the attachment line locations determined from these two data sets was $1 \%$ of the slat chord. The value of $\bar{R}$ computed from the computational solution was 193 and when using only data near the experimental locations it was 173. Finally, we wanted to see the effect of moving the pressure ports slightly away from the maximum pressure location. By taking the next available computational value on either side of the fake experimental port locations (3\% of the slat chord to the left of $\mathrm{C}_{\mathrm{pmax}}$ and $1 \%$ slat chord to the right) the attachment line location differed by $8 \%$ slat chord from the solution using the full computational data set. The $\overline{\mathrm{R}}$ value computed from the set of data with the ports moved away from the maximum pressure point was 235. Note, the value of $\overline{\mathrm{R}}$ computed from the actual experimental data was 222. Thus, as expected, the determination of the attachment line locations and the value of $\bar{R}$ from the measured pressures are dependent on the spacing and location of the pressure taps.

Two film objects were located on the upper surface of the slat. Object 37, a patch, was located at approximately $\eta=0.49$ and Object 40, a stamp, at approximately $\eta=0.95$. In Fig. 10, time traces for one film (aligned normal to the free stream flow direction) are shown for $\alpha=8^{\circ}, 12^{\circ}, 16^{\circ}$, and $24^{\circ}$. At $\alpha=8^{\circ}$ a very small amount of energy is seen in the signal. At $\alpha=12^{\circ}$ the flow is laminar, and at $\alpha=16^{\circ}$ and $24^{\circ}$ the flow is clearly turbulent. The data from Object 40, not shown, agree with the data at Object 37. Figure 11 shows the power spectra for each angle. At $\alpha=$ $8^{\circ}$ the energy in the spectra is concentrated at the low frequency end of the spectrum, at $\alpha=12^{\circ}$ the spectra has fallen to a level close to the noise floor of the instrumentation, and at $\alpha=16^{\circ}$ and $24^{\circ}$ full turbulent spectra appear to have developed. The skewness values support these descriptions of the flow on the upper surface.

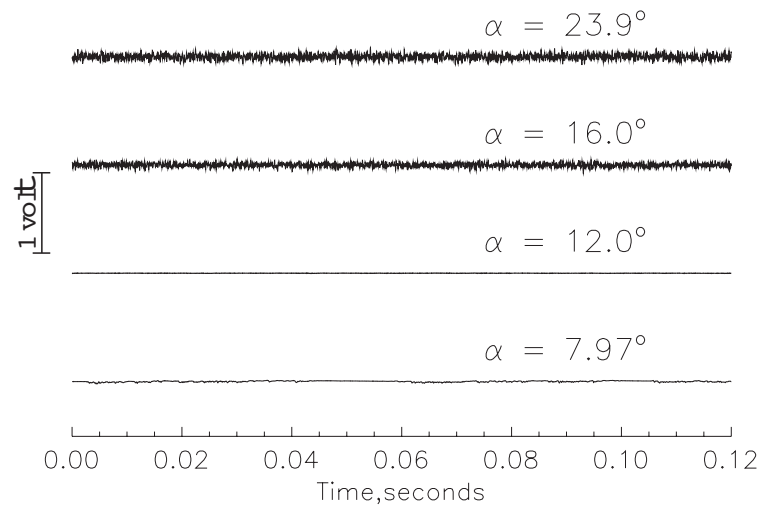

Figure 10. Time histories from film at $X_{\mathrm{le}} / \mathbf{c}=0.069, \eta=$ 0.49 from Object 37 on slat upper surface.

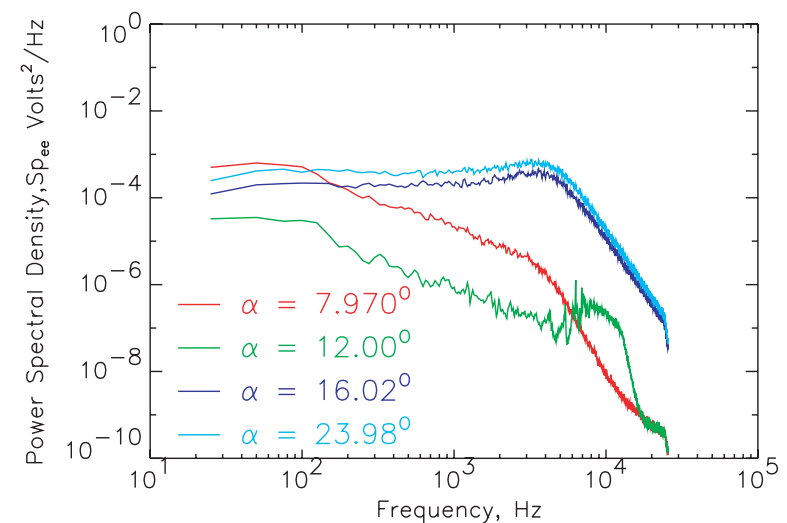

Figure 11. Spectra from film at $X_{\mathrm{le}} / \mathrm{c}=0.069, \eta=0.49$ from Object 37 on slat upper surface.

On the lower surface of the slat there were three principal film objects (all arrays), Object 34, centered at approximately $\eta=0.26$, Object 38 , centered at approximately $\eta=0.57$, and Object 39 , centered at approximately

\footnotetext{
${ }^{* *}$ Mark Chaffin, private communication
} 
$\eta=0.70$. For $\alpha=12^{\circ}$ and $16^{\circ}$, data from all three objects show the flow on the undersurface was laminar with small amplitude low frequency oscillations increasing in amplitude approaching the cusp. At $\alpha=24^{\circ}$, Objects 34 and 38 still show laminar flow, while Object 39 shows increasing disturbances that are traveling away from the attachment line. Object 39 was oriented so that one leg was perpendicular to the leading edge and ended near the cusp and the other leg was aligned parallel to the leading edge. Figure 12 shows the standard deviation of the hot-film signals for the leg perpendicular to the leading edge. For $\alpha=12^{\circ}$ and $16^{\circ}$ the attachment line was upstream or near to the beginning of the films on this leg of Object 39. Therefore the flow is heading in the negative $\mathrm{X}_{\mathrm{le}}$ direction, toward the slat cusp, and the small disturbances are increasing in amplitude as the flow approaches the cusp. At $\alpha=24^{\circ}$, the attachment line is farther back toward the slat cusp. In fact, cross correlations indicate that it may be in the vicinity of $\mathrm{X}_{\mathrm{le}} / \mathrm{c}=-0.045$, which is considerably different from the location estimated from the pressure taps. However as stated earlier the estimation of attachment line locations as determined from the pressure taps at $\alpha=24^{\circ}$ were subject to error. Also, correlating hot-film signals in a three dimensional flow can be difficult as well. The picture that emerged, however, from cross correlating the films on Object 39 at $\alpha=24^{\circ}$ was consistent in that for $\mathrm{X}_{\mathrm{le}} \mathrm{c}>-0.045$ the flow was headed toward the leading edge and in the spanwise direction toward the tip of the wing, while at $\mathrm{X}_{\mathrm{le}} / \mathrm{c}<-0.045$ it appeared headed toward the cusp. Correlations at all other angles were inconclusive as to direction due to the small signal levels. Figure 13 shows the spectra for one film at $X_{1 e} / c=-0.034$ on Object 39 for various angles of attack. Below $\alpha=24^{\circ}$ the energy is concentrated in the low frequency end of the spectra. At $\alpha=24^{\circ}$, the energy is spread out over a broader frequency range, but still at very small amplitude.

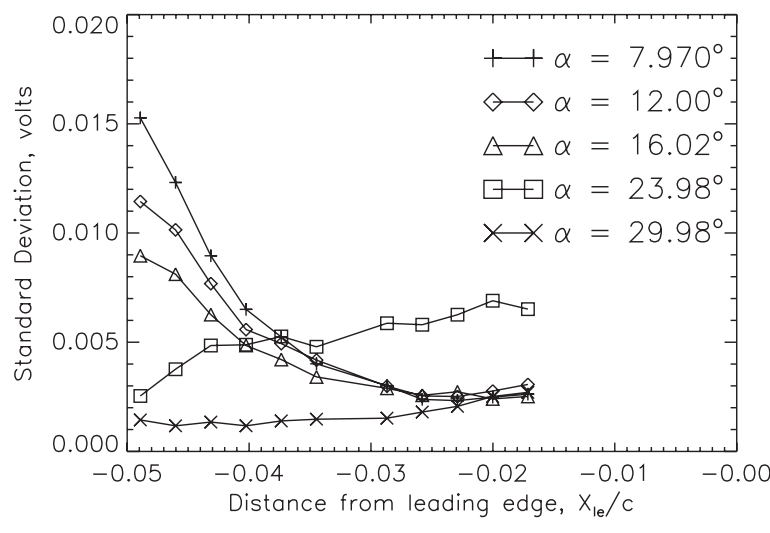

Figure 12. Standard deviation from films on Object 39 on the slat lower surface.

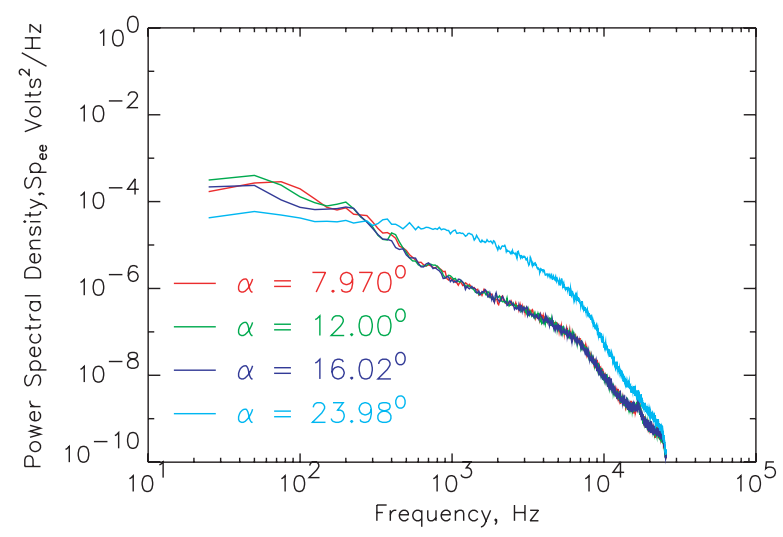

Figure 13. Spectra from one film on Object 39 located at $\mathrm{X}_{\mathrm{le}} / \mathrm{c}=\mathbf{- 0 . 0 3 4}$ on the slat lower surface.

In general for the slat, at $\alpha=12^{\circ}, 16^{\circ}$, and $24^{\circ}$ the attachment line is found to be laminar with the exception of small scale disturbances possibly emanating from the attachment line outboard on the slat at $\alpha=24^{\circ}$. On the upper surface the slat is laminar at $\alpha=12^{\circ}$ at mid chord, although transition may occur downstream. At $\alpha=16^{\circ}$ and $24^{\circ}$, on the slat upper surface, films at a mid chord station and near the tip show turbulent flow.

Figure 14 shows the spanwise variation of pressure for a portion of main element at $\alpha=24^{\circ}$ focusing on the area near the suction peak. The pressure profiles peak at $\eta=0.41$ and 0.65 and falloff as the root and tip are approached. At $\eta=0.95$ the effect of the tip vortex can be seen clearly by the sudden rise in suction at approximately $X_{\mathrm{le}} / \mathrm{c}=$ 0.25 . The change in the pressure due to angle of attack, at $\eta=0.71$, is shown in Fig. 15 . The values of $\bar{R}$, computed from several pressure rows on the main element are plotted in Fig. 16. The $\bar{R}$ values fall in the intermediate range where the attachment line can be laminar, transitional, or turbulent depending on the presence and strength of disturbances. Figure 17 shows the estimated locations of the attachment lines and the suction peaks in relation to the locations of films on three strip objects, 26, 27, and 28. 


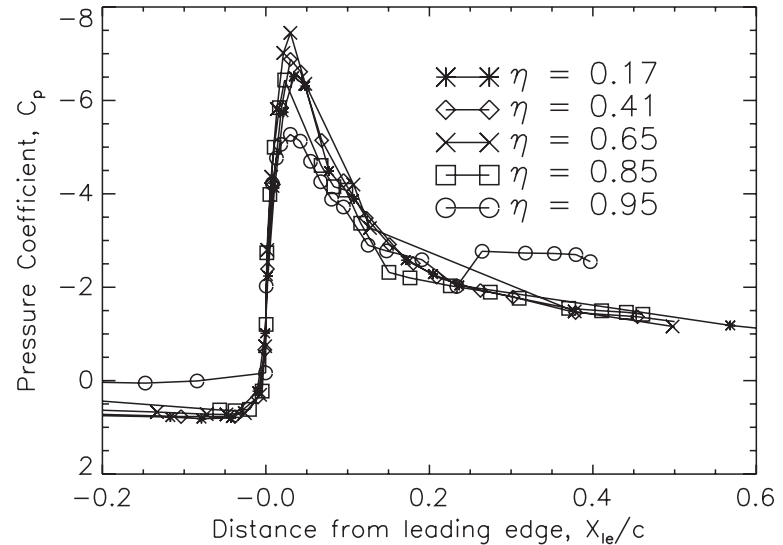

Figure 14. Main element pressure coefficient at several spanwise stations for $\alpha=\mathbf{2 4}^{\circ}$.

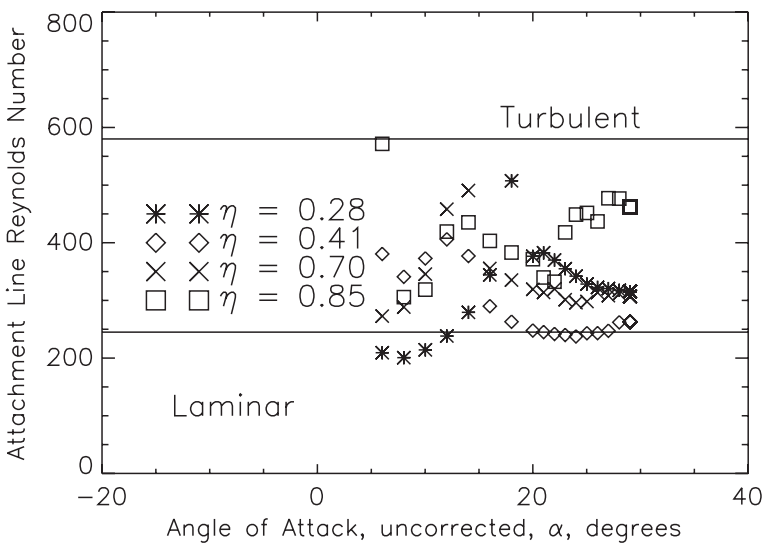

Figure 16. Main element attachment line Reynolds numbers.

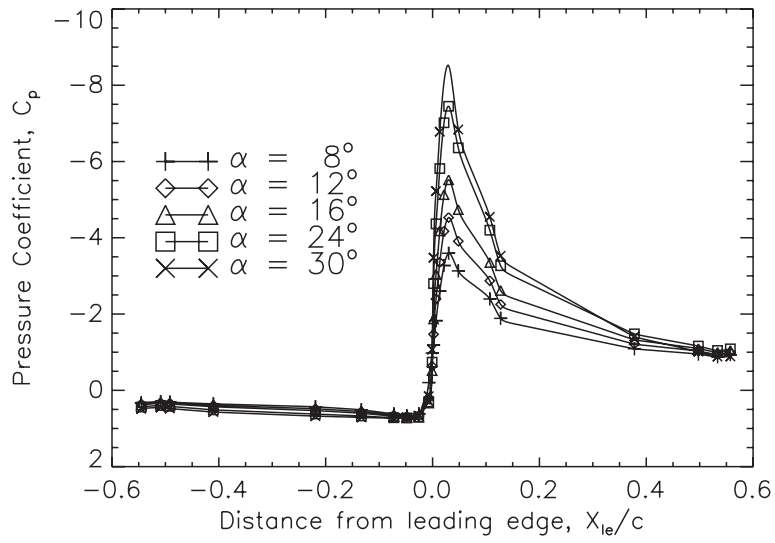

Figure 15. Main element pressure coefficient at several angles of attack at $\boldsymbol{\eta}=\mathbf{0 . 7 0}$.

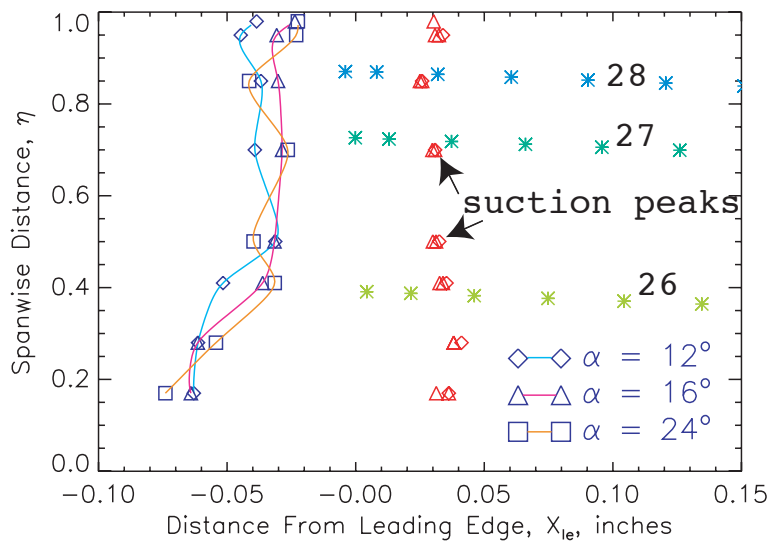

Figure 17. Relative positions of the main element attachment lines, suction peaks, and hot-films. Data from $\alpha=24^{\circ}$ are qualitative.

Hot-film measurements will be presented for Object 27 , which begins at approximately $\eta=0.72$. In general, the behavior of the flow was consistent across the span (excluding the root and tip). In Fig. 18, a peak occurs in the standard deviation for the film just downstream of the suction peak for $\alpha=12^{\circ}, 16^{\circ}$, and $24^{\circ}$. The skewness, Fig 19 , shows the classic change in sign as the flow switches from being predominately laminar to turbulent. Figure 20 shows the time series for $\alpha=12^{\circ}$. Clearly the flow over the first two films (upstream of the suction peak) is not entirely laminar. IR data acquired from the previous Langley test only showed a light and dark region that were interpreted as transition from laminar to turbulent. Hot-films are more sensitive than the global techniques and in this case provide more detail on the flow physics.

Since we were unable to locate any films near the attachment line and the attachment line Reynolds numbers were in the intermediate zone, we cannot say exactly what the state of the flow was between the attachment line and the suction peak. If the attachment line had been laminar, then transition would have begun during a favorable pressure gradient, which would be consistent with cross flow transition. However, the attachment line could also have been contaminated and have gone though varying degrees of transition, relaminarization, and retransition prior to reaching the suction peak. Estimations of the relaminarization parameter $K$ (both the 2-D and modified 3-D form) indicate that relaminarization was possible for $\alpha=12^{\circ}, 16^{\circ}$, and 24. The power spectra for the first film on the Object 27 for several angles of attack are shown in Fig. 21. The signals contain a fair amount of energy and have low frequency peaks at $\alpha=8^{\circ}, 12^{\circ}$, and $16^{\circ}$. At $\alpha=24^{\circ}$ the low frequency spike is less noticeable and there is a rise in the high frequency end of the spectrum. This type of behavior is reminiscent of that seen in hotwire signals from 


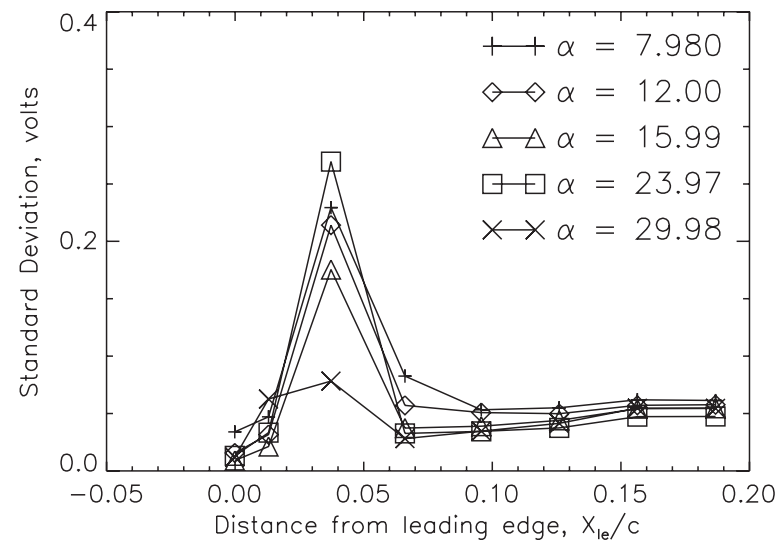

Figure 18. Standard deviation of hot-film signals on the main element, upper surface from Object 27.

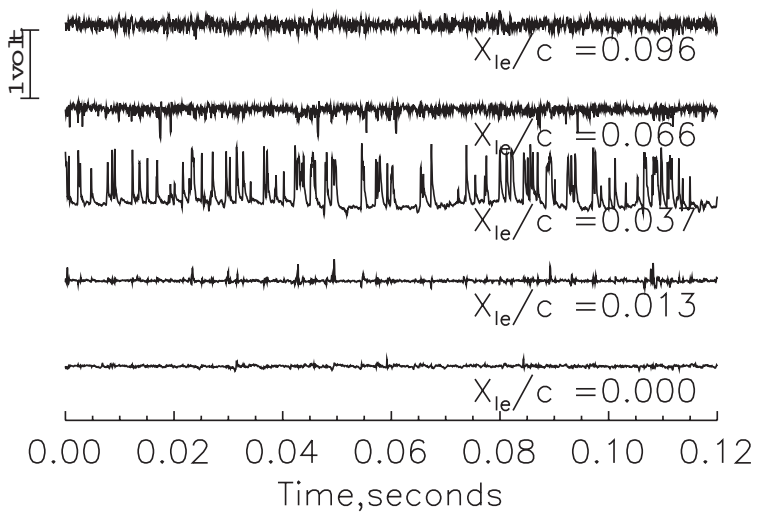

Figure 20. Times histories from Object 27, $\alpha=\mathbf{1 2}^{\circ}$.

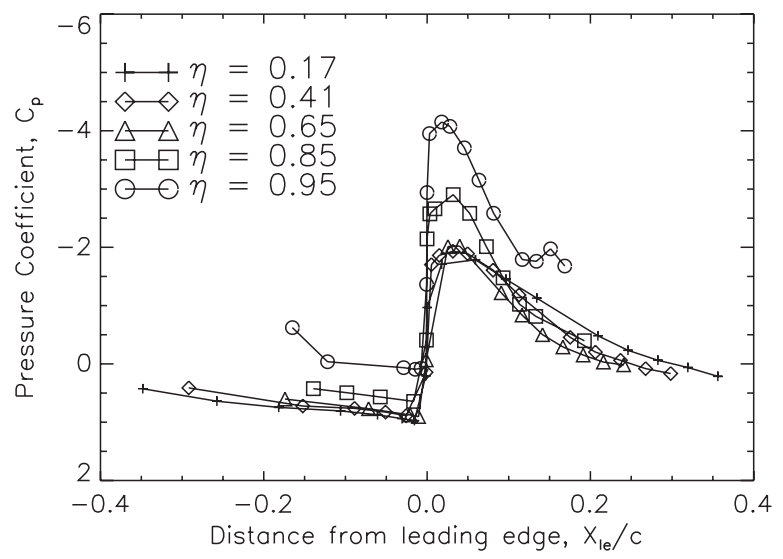

Figure 22. Pressure coefficient on the flap, $\alpha=24^{0}$.

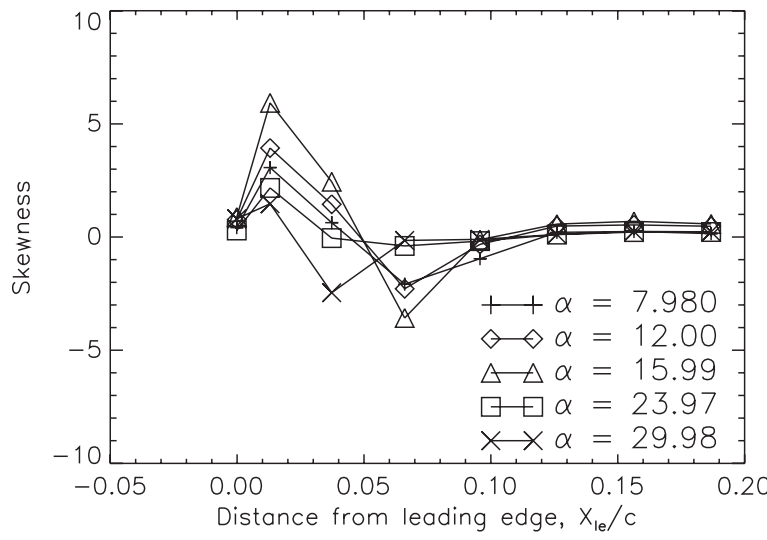

Figure 19. Skewness of hot film signals on the main element, upper surface from Object 27.

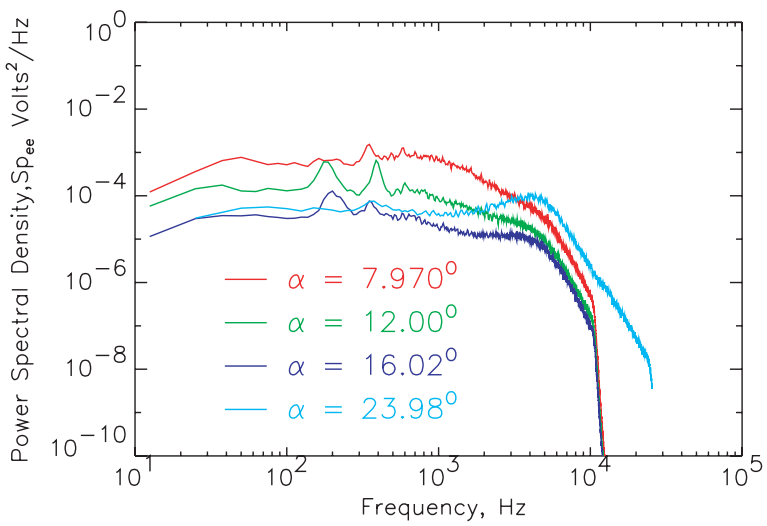

Figure 21. Spectra from one film from Object 27, located at $\mathrm{X}_{\mathrm{le}} / \mathrm{c}=\mathbf{0}$.

cross-flow transition studies by Bippes ${ }^{21}$ and Dagenhart and $\mathrm{Saric}^{22}$. A planned future stability analysis may clarify the meaning of the spectral spikes. Finally, although not shown, all films on the lower surface for the angles just discussed indicated fully turbulent flow. Unfortunately, due to the need to maintain a certain lead length, the films were only located at approximately the mid chord of the main. Therefore it is difficult to determine if transition occurred on the lower surface forward of the film locations.

Figure 22 shows the spanwise variation of the pressure on the flap at $\alpha=24^{\circ}$. Again the influence of the tip vortex is seen at $\eta=0.95$. The change in the pressures on the flap, at $\eta=0.41$, due to changes in angle of attack is shown in Fig. 23. The values of the attachment line Reynolds number, $\overline{\mathrm{R}}$, shown in Fig. 24, are remarkably consistent. The values all indicate the likelihood of a laminar attachment line at positive angles of attack. 


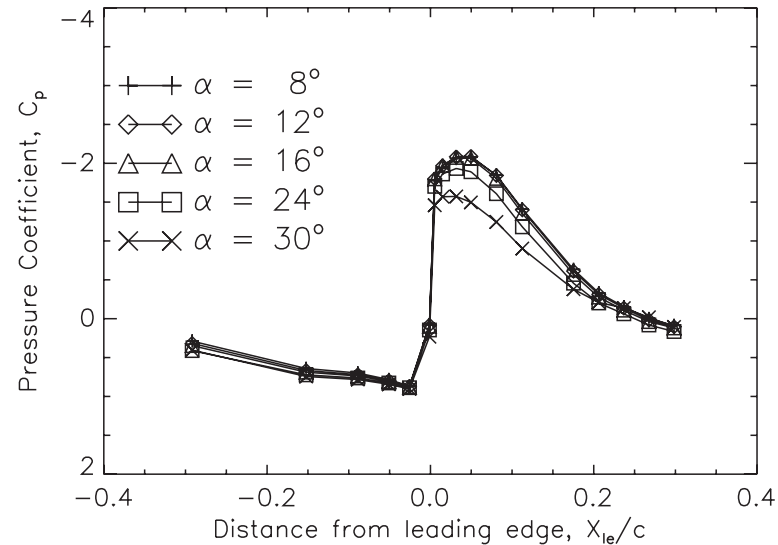

Figure 23. Pressure coefficient on flap at $\boldsymbol{\eta}=\mathbf{0 . 4 1}$.

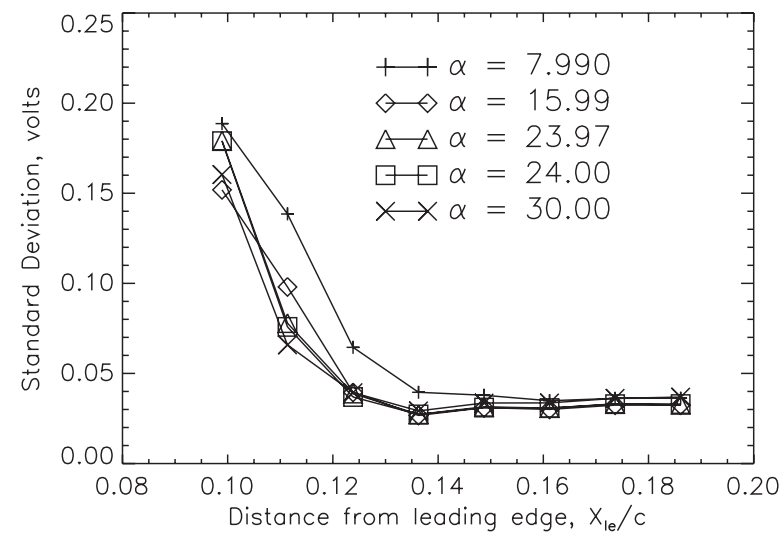

Figure 25. Standard deviation from films on upper surface of flap, Object 3, beginning at $\eta=0.31$.

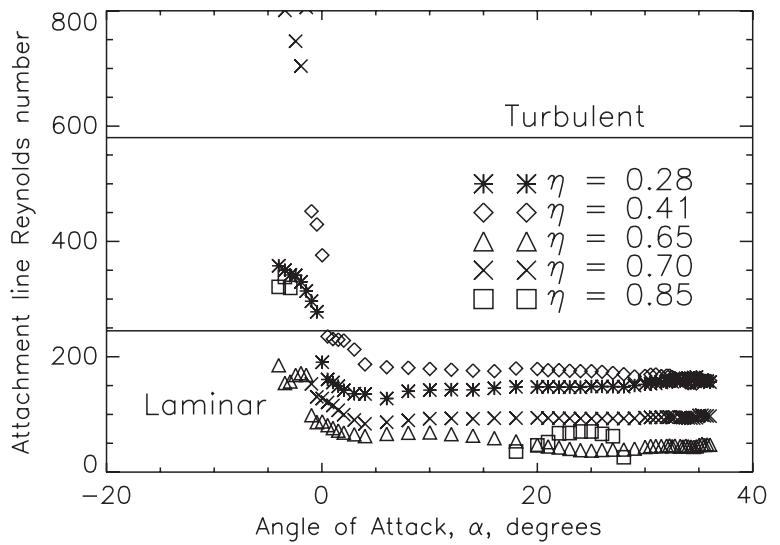

Figure 24. Flap attachment line Reynolds numbers.

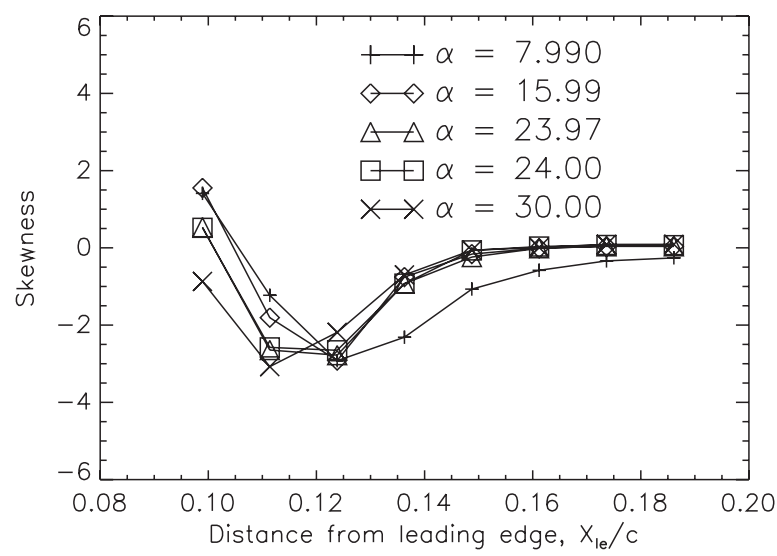

Figure 26. Skewness values from films on upper surface of flap, Object 3, beginning at $\eta=0.31$.

Several strip hot-film objects were located on the upper surface of the flap, all aft of the suction peak. The behavior of the film signals on the upper surface was consistent across the span of the flap (excluding the root and tip). The standard deviation for Object 3 , beginning at $\eta=0.31$, is shown in Fig. 25 . The values are decreasing as the flow travels downstream from the leading edge and then level off. Thus it appears that transition began upstream of the films. This is also seen in an examination of the skewness, presented in Fig. 26. The films appear to start at approximately the middle of the change in the skewness. The flow on the lower surface was more complicated than we expected. Figures 27 through 30 show the time series for several angles of attack for one film from each of four objects distributed spanwise on the lower surface of the flap and at approximately the mid span of the flap. The data show that near $\eta=0.32$ (Object 10) the flow was laminar, near $\eta=0.42$ (Object 11) the flow was turbulent, and finally near $\eta=0.55$ (Object 12) and $\eta=0.72$ (Object 13) the flow was varying degrees of transitional. Objects 11 and 13 are located in what may be the path of slat bracket wakes, although no flow visualization was done to verify this. In general, though, the data supports the existence of a laminar attachment line. Transition occurs in a fairly orderly fashion on the upper surface, while on the lower surface transition is very dependent on the spanwise location. 


\section{Summary}

The flow state over a generic trapezoidal three-element high-lift model wing model was studied using surface pressures and hot-films to provide non-proprietary code validation data. The attachment line on the slat was found to be laminar for $\alpha=12^{\circ}, 16^{\circ}$, and $24^{\circ}$, with the exception of one outboard spanwise station at $\alpha=24^{\circ}$ that showed disturbances possibly emanating from the attachment line. The flow on the upper surface of the slat at the mid chord was found to be laminar at $\alpha=12^{\circ}$ and turbulent at $\alpha=16^{\circ}$, and $24^{\circ}$. The values for $\bar{R}$ on the main element were in the range where the state of the boundary layer will depend on the presence and strength of external disturbances. The flow on the upper surface showed transition occurring directly aft of the suction peak and this was consistent over the span of the main element. Data upstream of the suction peak showed that the flow was not strictly laminar and may have signs of relaminarization and retransition. Data from the lower surface of the main element indicated turbulent flow. The state of the attachment line on the main element is inconclusive at this time. The flap attachment line was found to be laminar. Transition occurred in a uniform fashion on the upper surface. The lower surface of the flap showed a variation in the state of transition depending on the span wise location. These results clearly show the complexity associated with high-lift flows and the importance of using a myriad of measurement techniques for proper data interpretation and assessment.

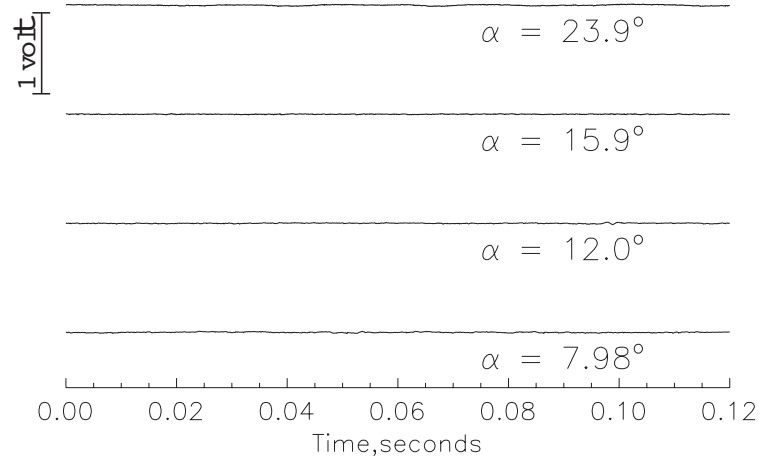

Figure 27. Time histories on lower surface of flap, $\eta=$ 0.32 .

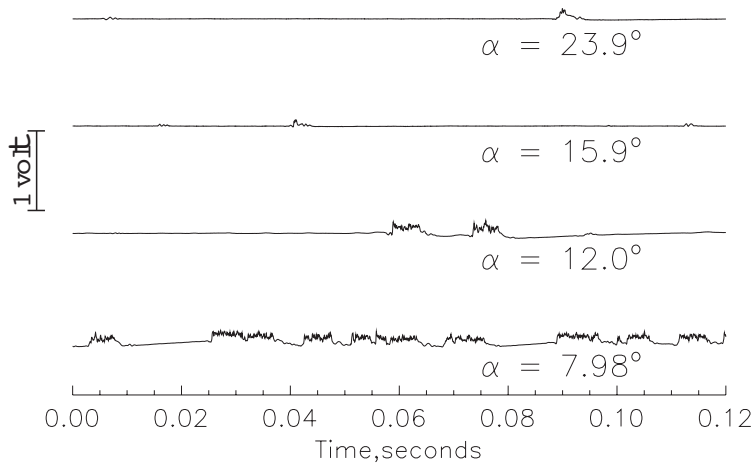

Figure 29. Time histories on lower surface of flap, $\eta=$ 0.55 .

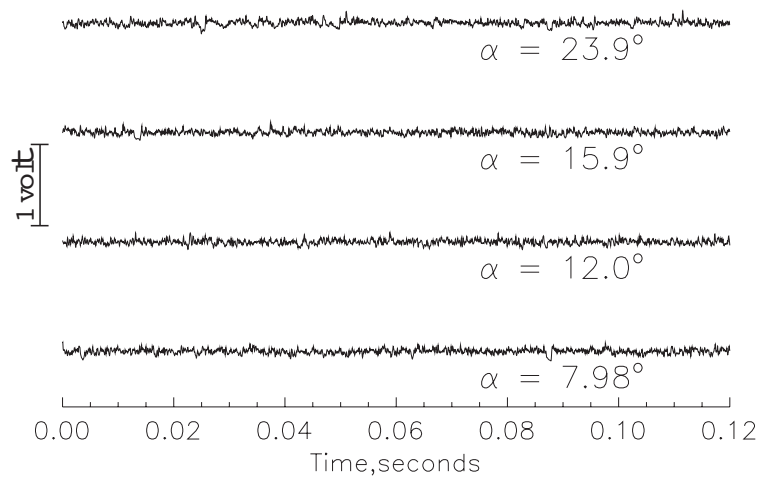

Figure 28. Time histories on lower surface of flap, $\eta=$ 0.42 .

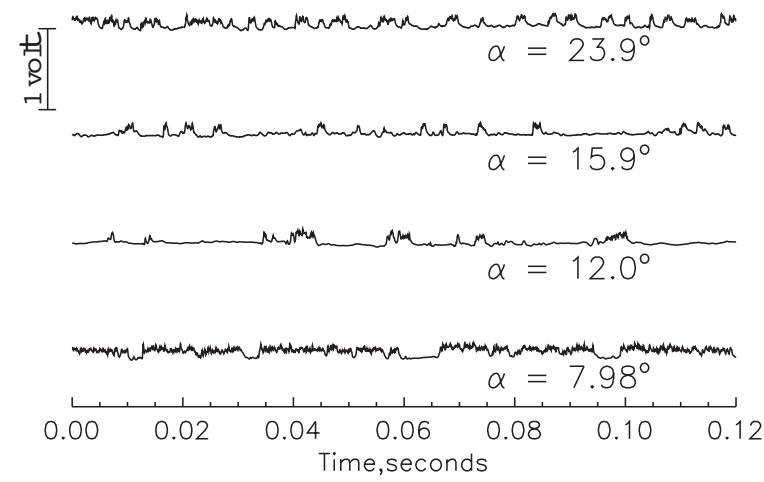

Figure 30. Time histories on lower surface of flap, $\eta=$ 0.72 . 


\section{Acknowledgments}

We would like to thank Rick Hopson and Johnny Mau for their incredible support in providing the hot-films, installing them in the wind tunnel, and setting up the anemometer systems. We would also like to thank their support staff for the countless hours spent connecting and checking out the films. Thanks also to the staff at the $14 \mathrm{x}$ 22 Wind Tunnel, especially Judi Hannon and Elliot Schoonover. We also thank Dan Neuhart for assisting in acquiring the hot-film data. Cathy McGinley would also like to thank Tony Washburn for his comments, both positive and negative, during the analysis of the data and the writing of this paper.

\section{References}

\footnotetext{
${ }^{1}$ Rumsey, C. L., and Ying, S. X., "Prediction of High Lift: Review of Present CFD Capability," Progress in Aerospace Sciences, Vol. 38, No. 2, 2002, pp. 145-180.

${ }^{2}$ Bertelrud A. "Transition on a Three-Element High Lift Configuration at High Reynolds Numbers," AIAA Paper 98-0703, Aerospace Sciences Meeting and Exhibit, 36th, Reno, NV, Jan. 12-15, 1998.

${ }^{3}$ McGinley C.B., Anders J.B., Spaid F.W., "Measurements of Reynolds Stress Profiles on a High-Lift Airfoil," AIAA Paper 98-2620, Applied Aerodynamics Conference, 16th, Albuquerque, NM, June 15-18, 1998.

${ }^{4}$ Ying SX, Spaid FW, McGinley CB, and Rumsey CL., "Investigation of Confluent Boundary Layers in High-Lift Flows," $J$ Aircraft, Vol. 36, No. (3), 1999, pp. 550-621.

${ }^{5}$ Rumsey CL, Gatski TB, Ying SX, and Bertelrud A., "Prediction of High-Lift Flows Using Turbulent Closure Models," AIAA $J$ Vol. 36, No. 5, 1998, pp. 765-774.

${ }^{6}$ J. Perraud, F. Moens and A. Séraudie, "Transition on a High Lift Swept Wing in the European Project EUROLIFT," AIAA-2003-3796, 21st AIAA Applied Aerodynamics Conference, Orlando, Florida, June 23-26, 2003.

${ }^{7}$ Stephanie M. Los and C. P. van Dam "Statistical Analysis of In-Flight Hot-Film Signals of Transitional Flows," AIAA1998-2440, Fluid Dynamics Conference, 29th, Albuquerque, NM, June 15-18, 1998.

${ }^{8}$ Poll, D.I.A., and Paisley, D.J., "On the Effect of Wing Taper and Sweep Direction on Leading Edge Transition," Aeronautical Journal, Vol. 89, March 1985, pp. 109-117.

${ }^{9}$ Launder, B.E. and Jones, W.P., "On the Prediction of Laminarisation," C.P. No. 1036, Ministry of Technology, Aeronautical Research Council, London, 1969.

${ }^{10}$ Bourassa, C., Thomas, F.O., Nelson, R.C., "Experimental Investigation of Turbulent Boundary Layer Relaminarization with Application to High-Lift Systems - Preliminary Results", AIAA 2000-4017, AIAA Applied Aerodynamics Conference, 18th, Denver, CO, Aug. 14-17, 2000.

11 Viswanath, P., Mukund, R., Narasimha, R, Crouch, J., "Relaminarization on Swept Leading Edges Under High-Lift Conditions,"AIAA-2004-99, 42nd AIAA Aerospace Sciences Meeting and Exhibit, Reno, Nevada, Jan. 5-8, 2004.

${ }^{12}$ Bertelrud, A., "Use of Empirical Transition Correlations for Flow Around High-Lift Configurations," AIAA 99-0541, 37 AIAA Aerospace Sciences Meeting and Exhibit, Reno, Nevada, Jan. 11-14, 1999.

13 Stanfield, J.H., and Betts, C.J., "Transition Detection Techniques in Use in the DRA Bedford Wind Tunnel", Flow visualization VII; Proceedings of the 7th International Symposium on Flow Visualization, Begell House, Inc., New York, 1995, p. 929-934.

${ }^{14}$ Dagenhart, J.R., Saric, W.S., Mousseux, M.C., and Stack, J.P, "Crossflow-Vortex Insatability and Transition on a 45Degree Swept Wing,” AIAA-89-1892, AIAA 20 ${ }^{\text {th }}$ Fluid Dynamics, Plasma Dynamics and Laser Conference, Buffalo, New York, 1989

${ }^{15}$ Neuhart, D.H., and McGinley, C.B., "Free-Stream Turbulence Intensity in the Langley 14- by 22-Foot Subsonic Tunnel," NASA TP-2004-213247, 2004

${ }^{16}$ Johnson, P.L., Jones, K.M., Madson, M.D., "Experimental Investigation of a Simplified 3D High Lift Configuration in Support of CFD Validation," AIAA-2000-4217, 18th AIAA Applied Aerodynamics Conference and Exhibit, Denver, CO, Aug. 14-17, 2000 .

${ }^{17}$ Rodgers, S.E., Roth, K., and Nash, S.M., "CFD Validation of High-Lift Flows with Significant Blockage Effects,” AIAA2000-4218, 18th AIAA Applied Aerodynamics Conference and Exhibit, Denver, CO, Aug. 14-17, 2000.

${ }^{18}$ Gentry, G.L., Quinto, P. F., Gatlin, G.G., and Applin, Z.T., "The Langley 14- by 22-Foot Subsonic Tunnel: Description, Flow Characteristics, and Guide for Users,” NASA TP-3008, 1990.

19 Chiles, H.R., "The Design and Use of a Temperature-Compensated Hot-Film Anemometer System for Boudary-Layer Flow Transition Detection on Supersonic Aircraft,” NASA TM 100421, 1988.
} 
${ }^{20}$ Bertelrud, A. and Graves, S., "Analysis of Flight Flow Characteristics in the Leading Edge Region of Swept Wings at Subsonic and Transonic Speeds," AIAA Paper 1994-2152, Biennial Flight Test Conference, 7th, Colorado Springs, CO, June 2023, 1994.

${ }^{21}$ Bippes, H. "Basic Experiments on Transition in Three-Dimensional Boundary Layers Dominated by Crossflow Instability," Progress in Aerospace Sciences, Vol. 35 pp. 363-412, 1999.

22 Dagenhart, J.R., and Saric, W.S., "Crossflow Stability and Transition Experiments in Swept-Wing Flow," NASA TP-1999209344, 1999. 